\section{BRAZIULIAN JOURNAL}

OF MEDICAL AND BIOLOGICAL RESFARCH

www.bjournal.com.br
ISSN 0100-879X

Volume 43 (9) 812-913 September 2010

BIOMEDICAL SCIENCES

AND

CLINICAL INVESTIGATION

Braz J Med Biol Res, September 2010, Volume 43(9) 843-852

doi: 10.1590/S0100-879X2010007500076

Luteinizing hormone reduction by the male potency herb, Butea superba Roxb.

S. Malaivijitnond, A. Ketsuwan, G. Watanabe, K. Taya and W. Cherdshewasart

The Brazilian Journal of Medical and Biological Research is partially financed by
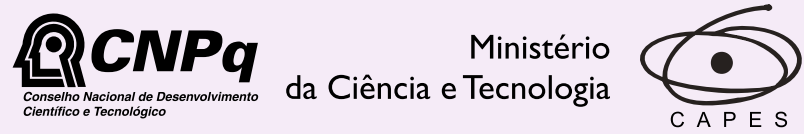

Ministério da Educação

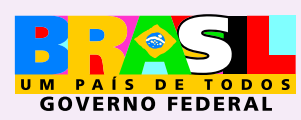

DFAPESP

Institutional Sponsors
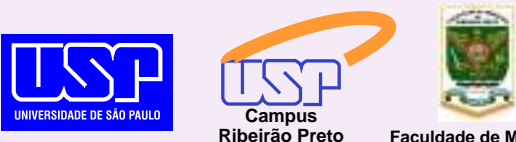

Ф SHIMADZU

GE Healthcare
Hotsite of proteomics metabolomics developped by: 


\title{
Luteinizing hormone reduction by the male potency herb, Butea superba Roxb.
}

\author{
S. Malaivijitnond ${ }^{1}$, A. Ketsuwan ${ }^{1,2}$, G. Watanabe ${ }^{3,4}$, K. Taya $^{3,4}$ and \\ W. Cherdshewasart ${ }^{1}$
}

1Primate Research Unit, Department of Biology, Faculty of Science, Chulalongkorn University, Bangkok, Thailand

2Interdisciplinary Program in Physiology, Graduate School, Chulalongkorn University, Bangkok, Thailand

${ }^{3}$ Laboratory of Veterinary Physiology, Tokyo University of Agriculture and Technology,

Tokyo, Japan

${ }^{4}$ Department of Basic Veterinary Science, the United Graduate School of Veterinary Science,

Gifu University, Gifu, Japan

\begin{abstract}
To determine if Butea superba Roxb., a traditional Thai male potency herb, has androgenic activity in 60-day-old male Wistar rats, we measured its effects on the pituitary-testicular axis and sex organs. Intact and orchidectomized adult male rats were subdivided into five groups (10 rats/group): distilled water, Butea superba (BS)-10, BS-50, BS-250, and testosterone propionate (TP). They received $0,10,50$, and $250 \mathrm{mg} \cdot \mathrm{kg}_{\text {body weight }}{ }^{-1} \cdot \mathrm{day}^{-1} \mathrm{BS}$ in distilled water by gavage and $6 \mathrm{mg} \cdot \mathrm{kg}^{\mathrm{body}}$ weight $^{-1}$. day ${ }^{-1}$ TP sc, respectively, during the 30-day treatment period. Blood was collected every 15 days and luteinizing hormone (LH), follicle-stimulating hormone (FSH) and testosterone were measured. Changes of weight and histological appearance of sex organs were determined at the end of the 30-day treatment and 15-day post-treatment periods. TP treatment reduced serum FSH and LH levels and significantly increased the weight of the seminal vesicles and epididymis, in accordance with histopathological changes, in both intact and orchidectomized rats. No changes in serum testosterone, LH, and FSH levels were observed in any of the intact rats treated with BS, but a significant increase in seminal vesicle weight was observed only in the BS-250 group. Although a significant reduction in serum LH was detected in the BS-50 and BS-250 groups of orchidectomized rats, no significant change in weight or histology of sex organs was observed. Thus, we conclude that $B$. superba needs endogenous testosterone to work synergistically to stimulate the accessory sex organ of intact animals and can potentially exhibit an $\mathrm{LH}$ reduction effect in orchidectomized animals.
\end{abstract}

Key words: Butea superba; Testosterone propionate; Testis; Seminal vesicle; Luteinizing hormone

\section{Introduction}

Butea superba Roxb. (Leguminosae: Fabales: Fabaceae), known in Thai as the red Kwao Krua, is a leguminous plant, which has been claimed to have aphrodisiac properties (1). Many products based on $B$. superba, such as a capsule formulation or gel cosmetic are claimed to support normal sexual function and to enhance sexual stamina, erectile capacity, sensitivity, and sexual performance, and are widely sold in local markets. It has also been reported that $B$. superba can improve erectile dysfunction in mature human males (2). It can increase intracavernous blood flow (3) and lead to erection via the inhibition of cGMP and
cAMP phosphodiesterase activity (3-5). Accordingly, investigations have been carried out to evaluate the androgenic activity of $B$. superba on the reproductive system of male animals $(6,7)$.

Manosroi et al. (6) treated intact male rats with a powdered suspension of $B$. superba at the doses of $2-1250 \mathrm{mg} /$ $\mathrm{kg}$ body weight for 8 weeks and found that sperm counts increased by $16 \%$ relative to the control group, but without a dose-response relationship. Thus, they concluded that $B$. superba may contain compounds, which have androgenic activity and that these may increase the release of gonad-

Correspondence: S. Malaivijitnond, Primate Research Unit, Department of Biology, Faculty of Science, Chulalongkorn University, Bangkok, 10330, Thailand. Fax: +66-2-218-5275. E-mail: Suchinda.m@chula.ac.th

Received October 9, 2009. Accepted July 30, 2010. Available online August 13, 2010. Published September $13,2010$. 
otropin-releasing hormone ( $\mathrm{GnRH}$ ) from the hypothalamus, increase the release of male sex hormone and, in turn, stimulate the growth of Sertoli and Leydig cells. However, they did not measure the hormonal levels related to the hypothalamic-pituitary-testicular axis (6). In contrast, it has been recently reported that feeding $B$. superba at doses of 150 and $200 \mathrm{mg} \cdot \mathrm{kg}$ body weight ${ }^{-1}$. day ${ }^{-1}$ for 90 days to intact male rats significantly reduced serum testosterone levels and slightly decreased serum luteinizing hormone (LH) levels, with a normal appearance of the testes observed under histological examination (7). The authors concluded that $B$. superba acts as an androgen disruptor, mainly through the alteration of testosterone biosynthesis or metabolism (7). Thus, an androgenic activity of $B$. superba in male animals has been suggested, but without strong experiments to support the conclusion. It has also been reported that $B$. superba at a dose of $250 \mathrm{mg} \cdot \mathrm{kg}$ body weight ${ }^{-1} \cdot$ day $^{-1}$ had an androgenic effect on female reproductive organs by increasing uterine thickness and the number of uterine glands in intact and ovariectomized rats (8).

On the basis of these considerations, we studied the androgenic activity of $B$. superba in intact and orchidectomized male rats by determining its effects on the pituitarytesticular axis and reproductive organs.

\section{Material and Methods}

\section{Animals}

Adult male Wistar rats aged 60 days and weighing 250$300 \mathrm{~g}$ were obtained from the National Laboratory Animal Center, Mahidol University, Nakhon Pathom, Thailand. They were housed in stainless steel cages with sawdust bedding at 5 animals/cage in a room with controlled lighting (lights on 6:00-20:00 h) and temperature $\left(25 \pm 1^{\circ} \mathrm{C}\right)$ at the Primate Research Unit, Department of Biology, Faculty of Science, Chulalongkorn University. The animals were fed rat chow (Pokaphan Animal Feed Co., Ltd., Thailand) and water ad libitum and were acclimatized to the surroundings for two weeks before starting the study. The experimental protocol was approved by the Animal Ethics Committee in accordance with the guide for the care and use of laboratory animals prepared by Chulalongkorn University.

\section{Experimental procedure}

Adult male rats used in this study were divided into two main groups: intact testes and orchidectomy. Each of these two main groups were randomly subdivided into five treatment groups (10 rats/group): distilled water (DW), Butea superba (BS)-10, BS-50, BS-250, and testosterone propionate (TP). DW, BS-10, BS-50, and BS-250 rats were gavaged with a suspension of $0,10,50$, and $250 \mathrm{mg} \cdot \mathrm{kg}$ body weight ${ }^{-1}$. day ${ }^{-1} B$. superba in $0.7 \mathrm{~mL}$ distilled water, respectively, during the treatment period. In the TP group, rats were injected subcutaneously with $6 \mathrm{mg} \cdot \mathrm{kg}$ body weight $^{-1}$. day ${ }^{-1}$ TP in $0.2 \mathrm{~mL}$ sesame oil. The experimental schedule was divided into three periods: pre-treatment, treatment and post-treatment for 15, 30, and 15 days, respectively. Rats were administered distilled water during the pre- and post-treatment periods by gavage for the BS group and subcutaneous injection for the TP group.

Intact group. Blood samples (1 $\mathrm{mL})$ were collected at 9:00-10:00 $\mathrm{h}$ on the first day and then every 15 days of the study period, designated as $D_{1}, D_{16}, D_{31}, D_{46}$, and $D_{61}$. Immediately after collection, all blood samples were centrifuged at $1000 \mathrm{~g}$ at $4^{\circ} \mathrm{C}$ for $20 \mathrm{~min}$, and sera were used for the determination of testosterone, $\mathrm{LH}$, and follicle-stimulating hormone (FSH). At the end of the treatment period, half the rats (i.e., 5 rats from each group) were randomly euthanized with ether. The testes, epididymis and seminal vesicles were dissected, cleaned of connective and other tissues, weighed and then fixed in $10 \%(\mathrm{w} / \mathrm{v})$ neutral buffered formalin solution and manipulated for histological examination as described previously (9). The remaining five rats in each group were euthanized at the end of the post-treatment period, and the testes, epididymis and seminal vesicles were processed as described. All rats were weighed once a week throughout the experimental period.

Orchidectomy group. Before submitting the rats to the pre-treatment period, a blood sample was collected at 9:00-10:00 $\mathrm{h}$ and the animals were then orchidectomized, and this day was designated as D-14. A 14-day recovery period was allowed before including the animals in the study. The experimental protocol for this group was similar to that described above for the intact group.

\section{Preparation of $B$. superba suspensions}

The tuberous roots of $B$. superba were collected from Lampang Province, Thailand (voucher specimen No. BCU 11046), as reported in Cherdshewasart et al. (10). The $B$. superba roots used throughout this study were from the same lot. The root was sliced and dried at $70-80^{\circ} \mathrm{C}$, pulverized in a mortar, and filtered through a $100-\mu \mathrm{m}$ mesh screen. The filtered powder was stored in an airtight container in the dark as a stock at room temperature. During treatment, the dried powder of $B$. superba was mixed with distilled water to obtain a stock suspension from which the required dilutions were made to a final volume of $0.7 \mathrm{~mL}$ of a final dose of $0,10,50$, and $250 \mathrm{mg} / \mathrm{kg}$ body weight (8). The suspension was administered to the rats at 8:00-9:00 h using a gastric feeding needle.

\section{Preparation of testosterone propionate}

TP powder (Sigma, Merck, USA) was weighed and dissolved in a small volume of absolute ethanol (GR Grade, Merck, USA). After the powder had completely dissolved, sesame oil was added and the solution was allowed to stand at room temperature with the ethanol evaporated. This stock solution was then diluted with sesame oil to provide a final dose of $6 \mathrm{mg} \cdot \mathrm{kg}$ body weight ${ }^{-1}$. day ${ }^{-1} \cdot 200 \mu \mathrm{L}$ sesame oil-1 ${ }^{-1}$. The stock TP solution was kept in dark bottles 
at room temperature until used. The solution was injected subcutaneously into rats between 8:00 and 9:00 h.

\section{Histological analysis}

After overnight fixation in formalin, the testes, epididymis and seminal vesicles were dehydrated in a series of ethanol gradients, cleared in xylene and embedded and blocked in paraffin prior to preparing $5-\mu \mathrm{m}$ sections and staining with hematoxylin and eosin, as reported $(9,11)$. The permanent slides of testis, epididymis and seminal vesicle sections were then examined under an Olympus light microscope and representative sections were photographed.

The number of seminiferous tubules in intact male rats that contained a small number of spermatozoa, defined here as being $<50 \%$ of the amount of spermatozoa observed in the normal seminiferous tubule of the control DW group, was evaluated histologically from the stained sections. Three sections/rat from each of 10 rats/group were counted.

\section{Determination of serum testosterone, LH, and FSH levels}

Serum testosterone levels were measured using the established radioimmunoassay technique of the World Health Organization (WHO) after the samples were extracted with ether (12).

Serum FSH and LH levels were measured by radioimmunoassay techniques using reagents obtained from the National Hormone and Pituitary Program. Iodination preparations were rat NIDDK-rat FSH-I-5 and rat LH-I-5. The antisera were anti-rat FSH-S11 and anti-rat LH-S11. The results obtained are reported in terms of the rat FSHRP-2 and rat LH-RP-3 reference standards (13).

To minimize interassay variations, all samples were run in a single assay. The intra-assay coefficients of variation for testosterone, $\mathrm{FSH}$, and $\mathrm{LH}$ were 10.6, 7.3, and 8.1\%, respectively.

\section{Statistical analysis}

Data are reported as means \pm SEM. The weights of the testis, epididymis and seminal vesicle collected at the end of the treatment and post-treatment periods were compared by the Student $t$-test. Differences in serum hormone levels between the pre-treatment, treatment and post-treatment periods in each group, and between the DW, BS, and TP groups in each experimental period, were analyzed by oneway analysis of variance (ANOVA) followed by the post hoc LSD test. In all cases significance was set at $P<0.05$.

\section{Results}

\section{Effect of $B$. superba on rats with intact testes}

Serum testosterone, FSH, and LH levels. When compared to the pre-treatment period $\left(D_{1}\right)$, serum testosterone levels in rats from the negative control (DW) group did not change significantly throughout the study period (Figure
1A), while the testosterone levels of the positive control (TPtreated) group were markedly and significantly increased throughout the treatment period $\left(D_{16-46}\right)$ and then returned to the pre-treatment level during the post-treatment period $\left(D_{61}\right)$. Since the assay can detect the exogenous-injected TP, in addition to endogenous testosterone levels, this is to be expected and does not address by itself the endogenous levels. The average serum testosterone levels in the groups receiving the three $B$. superba dose (BS) were not significantly different from each other or from those of the control DW group throughout the study period.

The average serum FSH levels of rats from the control
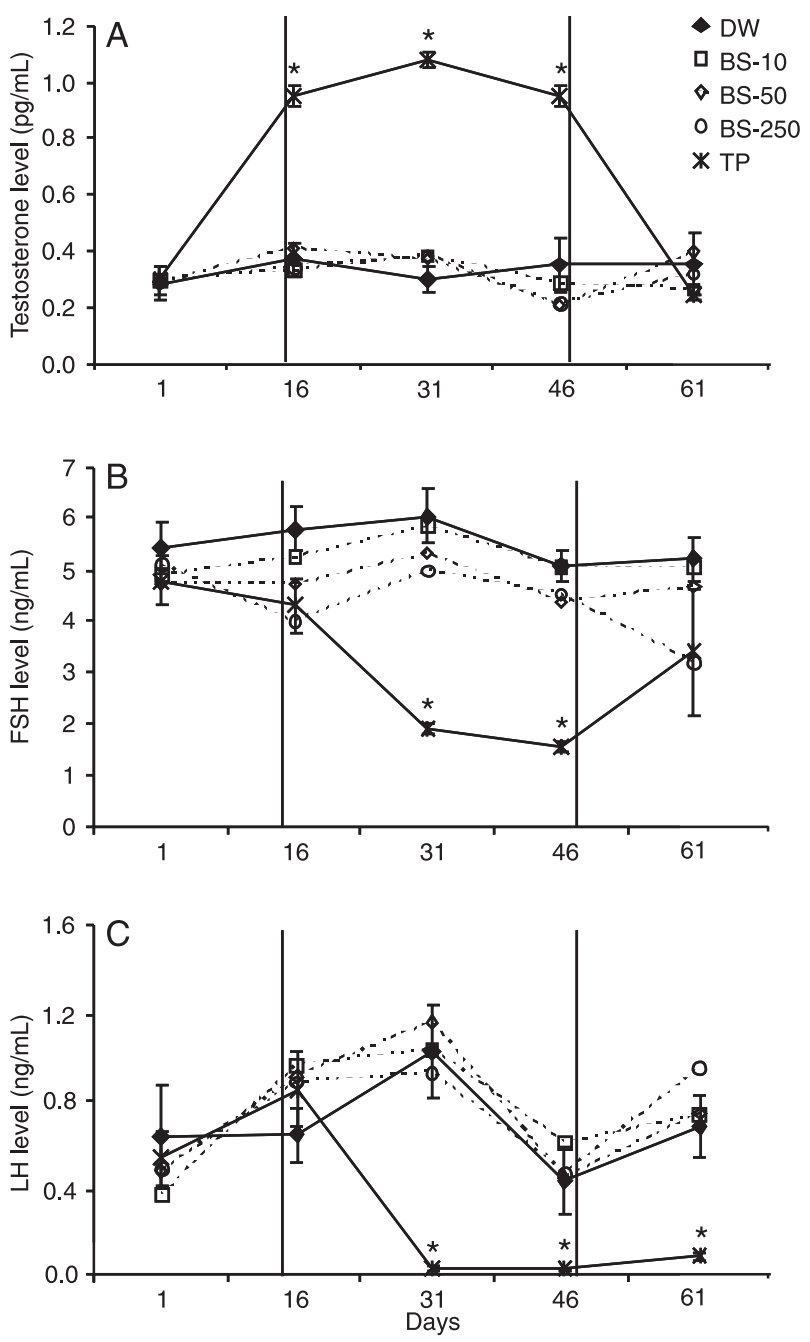

Figure 1. Serum levels of $A$, testosterone; $B$, follicle-stimulating hormone $(\mathrm{FSH})$ and $C$, luteinizing hormone $(\mathrm{LH})$ of intact male rats treated with distilled water (DW), Butea superba tuber powder at 10, 50, and $250 \mathrm{mg} \cdot \mathrm{kg}$ body weight ${ }^{-1} \cdot$ day $^{-1}$ (BS-10, -50 , and -250 , respectively) and testosterone propionate (TP) at 6 $\mathrm{mg} \cdot \mathrm{kg}$ body weight ${ }^{-1}$. day ${ }^{-1}$. Data are reported as means \pm SEM, except for all three BS groups where the SEM values are omitted for clarity. ${ }^{*} P<0.01$ compared to the DW group (ANOVA). 
(DW) and all three $B$. superba dose (BS) groups were not significantly different from each other throughout the study period, both within each treatment group over time, and between treatment groups (all P > 0.05; Figure 1B). In contrast, serum FSH levels were markedly and significantly decreased $(P<0.01)$ in the TP group during the treatment period $\left(D_{31}-D_{46}\right)$, but then returned to pre-treatment levels during the post-treatment period.

The changes in serum LH levels in all five groups of intact rats were broadly similar in pattern to those observed for the FSH levels (Figure 1C), with no significant changes within or between the DW control and all three BS treatment groups throughout the study period, but with a significant
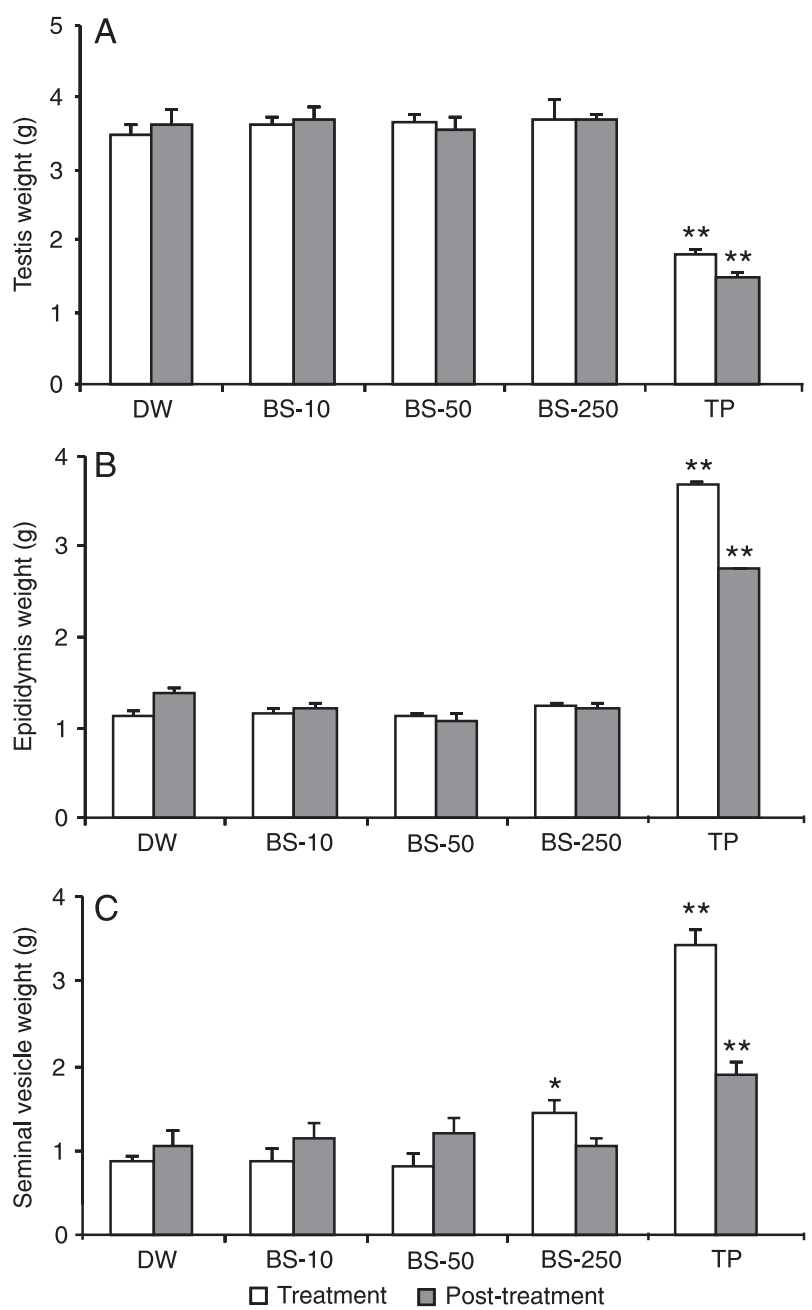

Figure 2. Tissue wet weights of $A$, testes; $B$, epididymis, and $C$, seminal vesicles of intact male rats treated with distilled water (DW), Butea superba tuber powder at 10,50, and $250 \mathrm{mg} \cdot \mathrm{kg}$ body weight ${ }^{-1} \cdot$ day $^{-1}$ (BS-10, -50 , and -250 , respectively) and testosterone propionate (TP) at $6 \mathrm{mg} \cdot \mathrm{kg}$ body weight ${ }^{-1} \cdot$ day $^{-1}$. Data are reported as means \pm SEM. ${ }^{*} P<0.05$ and ${ }^{* *} P<0.01 \mathrm{com}-$ pared to the DW group. (ANOVA). decrease in serum LH levels being observed in the TP group from $D_{31}$ through $D_{61}$ of the post-treatment period. In slight contrast was the weak recovery of serum LH levels in the TP-treated group during the post-treatment period.

\section{Body weight and reproductive organ weight}

Relative to $D_{1}$, the mean rat body weights increased gradually over the 61-day period for the control (DW), TP and all three BS treatment groups, but there was no significant difference between them or compared to the DW control group at each time throughout the study period (data not shown). The body weight gain of the TP group was numerically lower than that of the DW and BS groups but there was no statistically significant difference between them.

There were no significant differences in average testis weights between the treatment and post-treatment periods in the DW and in each BS group, or between the control (DW) and all three BS groups (Figure 2A). In contrast, the average testis weight of the TP group during both the treatment and post-treatment periods was significantly lower than those of the control DW and BS treatment groups $(P<0.01)$ and, additionally, the testis weight of TP-treated rats during the post-treatment period was significantly lower than that observed during the treatment period $(P<0.05)$.

There were also no differences in average epididymis weight between the treatment and post-treatment periods in the control DW group and in each of the BS treatment groups, or between the control and all three BS treatment groups during the treatment and post-treatment periods (Figure 2B). In contrast, the average epididymis weight of the TP group during both the treatment and post-treatment periods was significantly higher than those of the DW and BS groups $(P<0.01)$ and, additionally, the weight during the post-treatment period was significantly lower than that during the treatment period $(P<0.05)$.

Changes in average seminal vesicle weight in the control and all three BS groups were similar to those of the epididymis weights, except that the seminal vesicle weight of the BS-250 group was higher than those of the control DW and the BS-10 and BS-50 treatment groups $(P<0.05$; Figure $2 \mathrm{C}$ ). In contrast, the average seminal vesicle weight of the TP group during both the treatment and post-treatment periods was significantly higher than those of the DW and BS treatment groups $(P<0.01)$, while the weight during the post-treatment period was significantly lower than that during the treatment period $(P<0.05)$.

\section{Histology of testis, epididymis and seminal vesicle}

The histology of the testis in DW and BS-treated rats during the treatment period showed numerous spermatogenic cells in various stages, including primary spermatocytes (S1), secondary spermatocytes (S2), spermatids (S3), and spermatozoa (S) (Figure 3). In contrast, the testis of TP-treated rats showed a thin layer of spermatogenic cells and a small number of spermatozoa when compared to the 


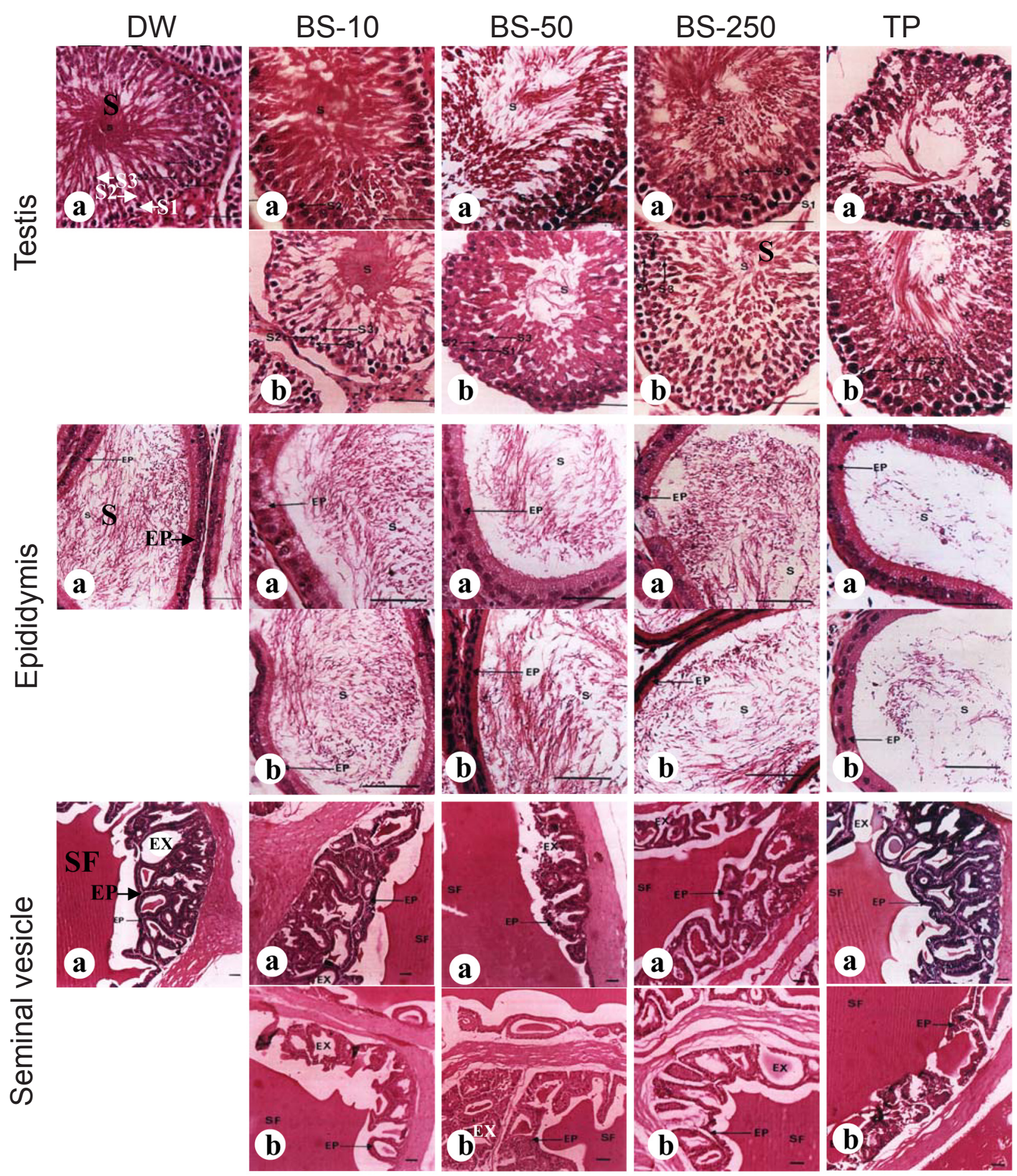

Figure 3. Testis, epididymis and seminal vesicle morphology of intact male rats treated with distilled water (DW), Butea superba tuber powder at 10,50, and $250 \mathrm{mg} \cdot \mathrm{kg}$ body weight ${ }^{-1} \cdot$ day $^{-1}$ (BS-10, -50 , and -250 , respectively) and testosterone propionate (TP) at 6 mg $\cdot \mathrm{kg}$ body weight ${ }^{-1} \cdot$ day $^{-1}$ at the end of treatment (a) and post-treatment (b) periods. $\mathrm{S} 1$ = primary spermatocyte; $\mathrm{S} 2=$ secondary spermatocyte; S3 = spermatid; $\mathrm{S}=$ spermatozoan; $\mathrm{EP}=$ epithelial cell; $\mathrm{EX}=$ papilla folding; $\mathrm{SF}=$ seminal fluid. Scale bars $=50 \mu \mathrm{m}$. 
Table 1. Percent of seminiferous tubules that show a lower sperm number $(<50 \%)$ in intact male rats treated with distilled water (DW), Butea superba (BS) tuber powder at 10,50, and $250 \mathrm{mg} \cdot \mathrm{kg}$ body weight ${ }^{-1}$.day $^{-1}$ (BS-10, -50 , and -250 , respectively) and testosterone propionate (TP) at $6 \mathrm{mg} \cdot \mathrm{kg}^{\text {body weight }}{ }^{-1} \cdot$ day $^{-1}$.

\begin{tabular}{lcc}
\hline Treatment & \multicolumn{2}{c}{$\begin{array}{c}\text { Percent of seminiferous tubules showing } \\
\text { impaired spermatogenesis }\end{array}$} \\
\cline { 2 - 3 } & Treatment & Post-treatment \\
\hline DW & $24.15 \pm 0.69^{\mathrm{a}}$ & $23.23 \pm 0.89^{\mathrm{a}}$ \\
BS-10 & $25.67 \pm 0.48^{\mathrm{a}}$ & $24.28 \pm 1.05^{\mathrm{a}}$ \\
BS-50 & $23.96 \pm 0.80^{\mathrm{a}}$ & $23.77 \pm 1.96^{\mathrm{a}}$ \\
BS-250 & $25.04 \pm 1.45^{\mathrm{a}}$ & $24.13 \pm 1.19^{\mathrm{a}}$ \\
TP & $47.86 \pm 2.75^{\mathrm{b}}$ & $28.01 \pm 2.04^{\mathrm{c}}$ \\
\hline
\end{tabular}

Means with different lower case superscript letters are significantly different from each other $(P<0.05$, ANOVA).

control DW and all three BS-treated groups. The testis histology for the DW and BS groups did not differ between the treatment and post-treatment periods, but spermatogenic cell types seemed to increase in the TP group during the post-treatment period. Thus, the percent of seminiferous tubules with a low sperm number counted (or impaired spermatogenesis) did not differ between the DW and the three BS-treated groups, but was significantly higher $(\mathrm{P}<$ 0.01 ) in the TP group, which was in a partially recovered state during the post-treatment period (Table 1).

During the treatment period, the histology of the epididymis of control DW rats and of rats treated with all three doses of BS showed a similar composition mainly consisting of columnar and cuboidal ciliated epithelial cells (EP) with numerous spermatozoa (S) inside the tubules (Figure 3). Comparable to the reduction of sperm production in the testis, the sperm number in the epidymidis of TP-treated rats was also decreased, and the columnar ciliated cells showed a thicker layer. The histology of the epididymis of the control DW group and of all three BS-treated groups did not differ between the treatment and post-treatment periods. However, during the post-treatment period the epididymis of the TP group showed a thinner layer of epithelial cells.

The seminal vesicles of control DW rats and of those treated with all three doses of BS showed a high papilla folding (EX) of the tubular glands and muscular layers (Figure 3). A whitish-yellow viscous material (SF) was secreted into the lumen of the seminal vesicle (Figure 3 ). In the BS-250 group, the folded tubular glands were similar to those of other BS groups, but the amount of secretory material was higher. In the TP group, the number of folded tubular glands and the level of secretory material were higher than those of the DW and BS groups. While there were no differences in seminal vesicle histology between the treatment and post-treatment periods in the DW and BS groups, in the TP group the number of folded tubular
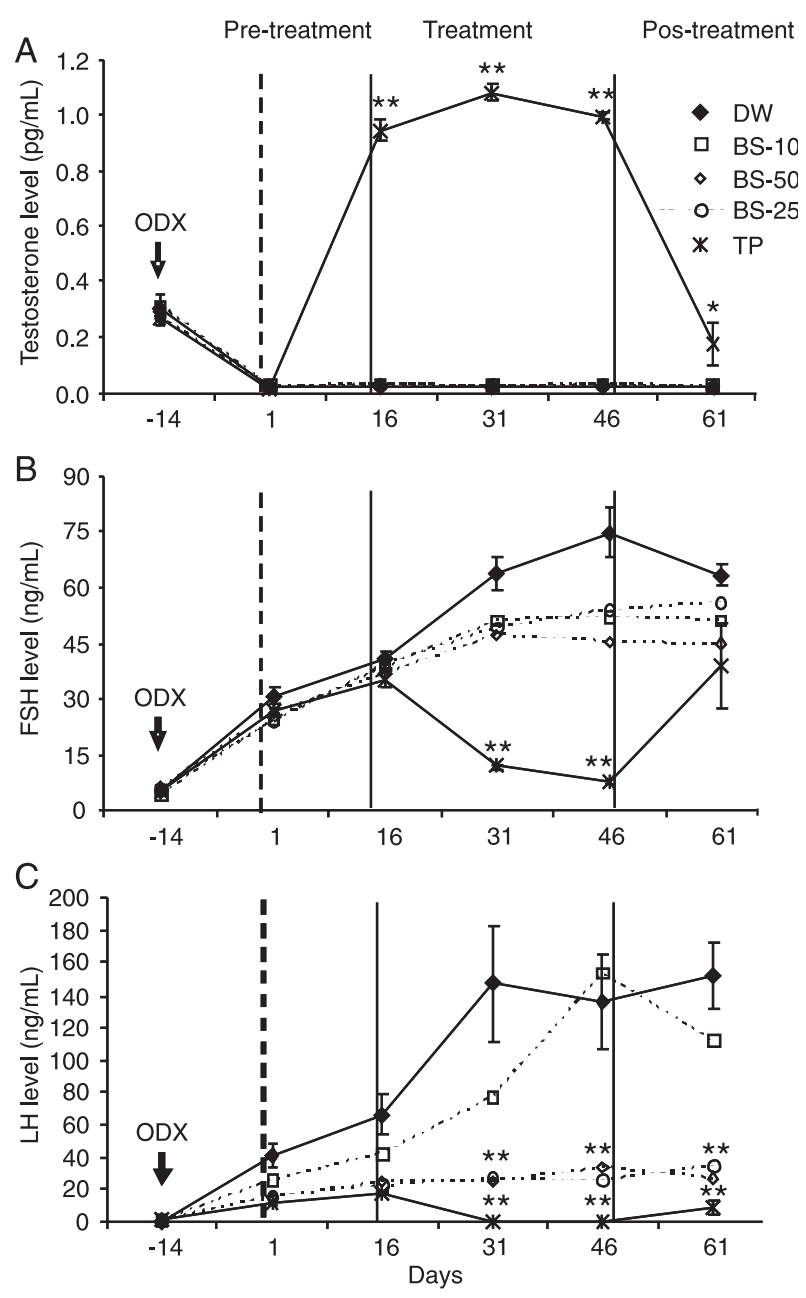

Figure 4. Serum levels of $A$, testosterone; $B$, follicle-stimulating hormone (FSH), and $C$, luteinizing hormone (LH) of orchidectomized rats treated with distilled water (DW), Butea superba tuber powder at 10,50 , and $250 \mathrm{mg} \cdot \mathrm{kg}^{\text {body weight }}{ }^{-1} \cdot \mathrm{day}^{-1}$ (BS-10, -50 , and -250 , respectively) and testosterone propionate (TP) at $6 \mathrm{mg} \cdot \mathrm{kg}$ body weight ${ }^{-1} \cdot \mathrm{day}^{-1}$. Data are reported as means \pm SEM, except for all three BS groups where the SEM values are omitted for clarity. ${ }^{*} \mathrm{P}<0.05$ and ${ }^{* *} \mathrm{P}<0.01$ compared to the DW group (ANOVA).

glands and the quantity of secretion material were lower during the post-treatment period than during the treatment period (Figure 3).

\section{Effects of $B$. superba in orchidectomized rats}

Serum testosterone, $\mathrm{FSH}$, and $\mathrm{LH}$ levels. There were no significant differences between the five groups before $\left(D_{-14}\right)$ and after $\left(D_{1}\right)$ orchidectomy. However, for 14 days after orchidectomy, serum testosterone levels of rats were significantly decreased $(286.1 \pm 56.9$ and $17.7 \pm 2.1 \mathrm{pg} / \mathrm{mL}$ for $D_{-14}$ and $D_{1}$, respectively; Figure $4 A$ ). Compared to $D_{1}$, 
there were no significant changes in serum testosterone levels in the DW and BS groups throughout the study period, whereas the serum testosterone levels of TP-treated rats were significantly increased $(P<0.01)$ during the treatment period to over a 3-fold higher level than that prior to orchidectomy. Although serum testosterone levels decreased during the post-treatment period, and fell back below the pre-orchidectomy level, they were still significantly higher than the $D_{1}$ level $(P<0.05)$.

In agreement with the decrease in serum testosterone levels, serum FSH levels of rats were significantly increased by 14 days after orchidectomy (5.3 \pm 0.3 and $26.4 \pm 2.9 \mathrm{ng} / \mathrm{mL}$ for $D_{-14}$ and $D_{1}$, respectively; Figure $4 B$ ), and compared to the $D_{1}$ levels, continued to increase significantly throughout the study period in the DW and BS groups. Although the serum FSH levels in all three BS-treated groups were numerically lower than those of the DW group, there was no statistically significant difference. In contrast, during treatment, the serum FSH levels of TP-treated rats were significantly lower than those of the control DW group $\left(D_{31}-D_{46}\right)$, before rising again during the post-treatment period.

Likewise, in agreement with the changes in serum testosterone and FSH levels, serum LH levels of rats were significantly increased by 14 days after orchidectomy $(0.7$ \pm 0.2 and $21.4 \pm 3.3 \mathrm{ng} / \mathrm{mL}$ for $D_{-14}$ and $D_{1}$, respectively; Figure $4 C)$. Serum LH levels of control DW rats $(P<0.01)$ and of the BS-10 treatment group $(P<0.05)$ increased significantly throughout the study period but no statistically significant differences were observed between these two groups. In contrast, the serum LH levels of rats from the BS-50 and BS-250 treatments were significantly lower than those of the control DW group at $D_{31}-D_{61}(P<0.01)$. The serum LH levels of TP-treated rats started to be lower than those of the DW group from $D_{16}$, and were significantly different on $D_{31}-D_{61}(P<0.01)$.

\section{Body weight and reproductive organ weight}

Relative to $D_{-14}$, the mean rat body weights gradually increased numerically over the 75-day period for the con- trol DW, TP, and all three BS treatment groups, but with no significant difference between each other or compared to the DW group at each time throughout the study period (data not shown). Thus, at least under these unrestricted food and standardized conditions, the BS treatments had no effect on body weight. In contrast, the body weight gain of TP-treated rats at the end of the study period was significantly higher than those of the control DW and all three BS treatment groups $(124.5 \pm 10.8 \mathrm{~g}$ vs $70.2 \pm 7.9 \mathrm{~g}$, respectively) but there were no differences between DW, BS10, BS50, and BS250 groups.

There were no significant differences in the average epididymis and seminal vesicle weights between the treatment and post-treatment periods within the control DW and each of the three BS treatment groups, or between the control DW and all three BS treatment groups (Figure $5 A, B)$. In contrast, the average epididymis and seminal vesicle weights of TP-treated rats during both the treatment and post-treatment periods were significantly higher than those of the DW and BS groups $(P<0.01)$, and the weights during the post-treatment period were significantly lower than during the treatment period $(P<0.05)$.

\section{Histology of the epididymis and seminal vesicle}

Orchidectomized rats showed the absence of stereocilia in the ductus tubulus epididymis, a smaller lumen size with many layers of vacuoles in the epithelial lining (EP) and the absence of spermatozoa in the lumen during the treatment period compared to intact male rats (Figure 6). There were no differences in the histology of the epididymis between the treatment and post-treatment periods in the control DW or in each of the three BS doses, nor between the control DW and all three BS groups (Figure 6). In contrast, during the treatment period the tubular epithelium of the ductus epididymis of the TP group was pseudostratified, consisting of tall columnar principal cells with long sterocilia and small basal cells without vacuoles. During the post-treatment period, the number of stereocilia and their height in the tubular epithelial cells were diminished.

After orchidectomy the DW control and BS-treated rats

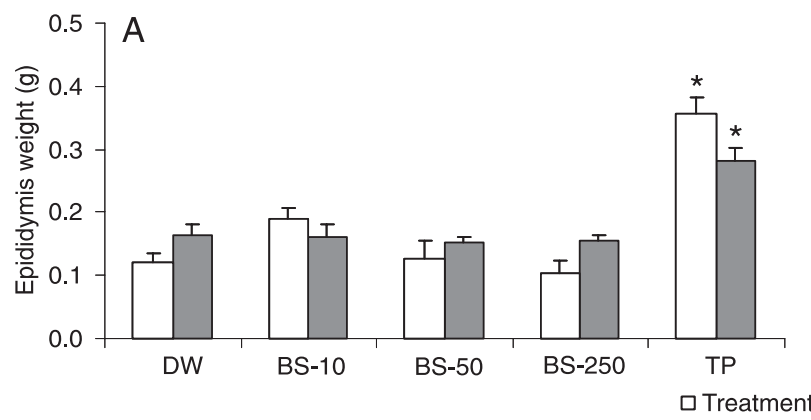

Figure 5. Tissue wet weights of the $A$, epididymis and $B$, seminal vesicles of orchidectomized rats treated with distilled water (DW), Butea superba tuber powder at 10,50 , and $250 \mathrm{mg} \cdot \mathrm{kg}_{\text {body weight }}{ }^{-1} \cdot$ day $^{-1}$ (BS-10, -50 , and -250 , respectively) and testosterone propionate (TP) at $6 \mathrm{mg} \cdot \mathrm{kg}$ body weight ${ }^{-1} \cdot \mathrm{day}^{-1}$. Data are reported as means $\pm \mathrm{SEM}$. ${ }^{*} \mathrm{P}<0.01$ compared to the DW group (ANOVA). 


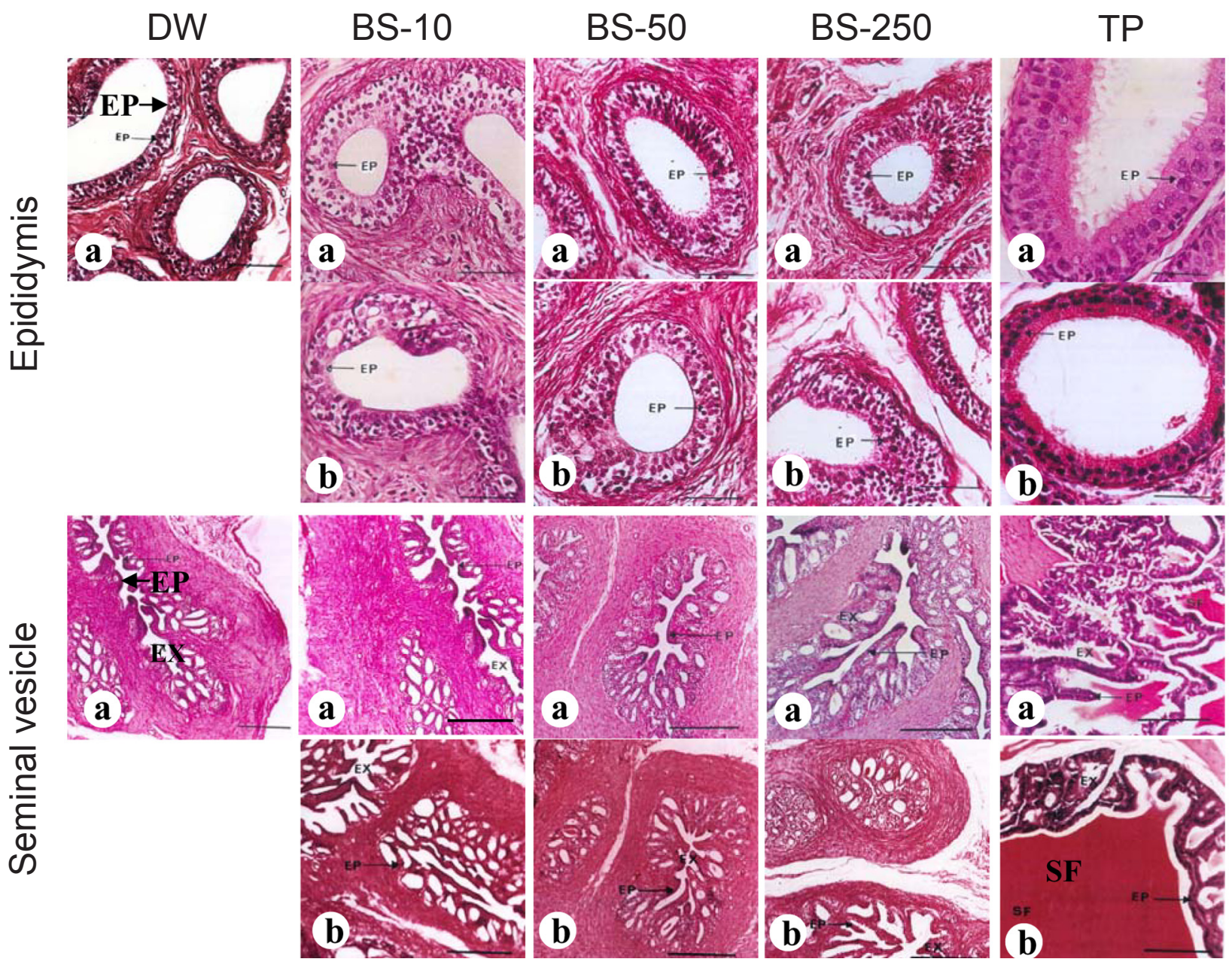

Figure 6. Epididymis and seminal vesicle morphology of orchidectomized rats treated with distilled water (DW), Butea superba tuber powder at 10, 50, and $250 \mathrm{mg} \cdot \mathrm{kg}^{\text {body weight }}{ }^{-1} \cdot$ day $^{-1}$ (BS-10, -50 , and -250 , respectively) and testosterone propionate (TP) at 6 $\mathrm{mg} \cdot \mathrm{kg}$ body weight ${ }^{-1} \cdot \mathrm{day}^{-1}$ at the end of treatment (a) and post-treatment (b) periods. $\mathrm{EP}=$ epithelial cell; $\mathrm{EX}=$ papilla folding; $\mathrm{SF}=$ seminal fluid. Scale bars $=50 \mu \mathrm{m}$.

showed a decrease in the number of epithelial foldings (EX) and an absence of seminal secretion (SF; Figure 6). In contrast, TP-treated rats revealed a highly developed papilla folding pattern of the seminal vesicle tubular glands with numerous primary, secondary, and tertiary foldings, filled with secretory material, which then decreased during the post-treatment period.

\section{Discussion}

Although the products prepared from B. superba are widely consumed for various reproduction-related activities in men, the androgenic activity of $B$. superba is not known. The present study was, therefore, carried out to determine the androgenic effects of $B$. superba on the pituitary-testis axis and the reproductive organs (weights and histology) of intact and orchidectomized adult male rats. Distilled water and TP (6 mg $\mathrm{kg}$ body weight ${ }^{-1} \cdot$ day $\left.^{-1}\right)$ were used as negative and positive controls of androgenic activity, respectively $(8,14-17)$. The doses of $B$. superba used in this study, 10 , 50 , and $250 \mathrm{mg} / \mathrm{kg}$ body weight, were based on previous studies carried out with female $(8)$ and male $(6,7)$ rats.

The response of body weight gain of adult male rats to TP treatment was decreased in intact and increased in orchidectomized rats, despite the fact that orchidectomy decreased the body weight gain in the DW control group. These changes are in accordance with previous reports (14$16)$, but are different from the reported effects of estrogens and ovariectomy $(8,18,19)$.

The positive control (TP-treated group) showed the expected androgenic effects occurring in intact male rats that is decreased serum LH and FSH levels. Indeed, after FSH and LH secretion from the pituitary gland is reduced (20), the endogenous testosterone secretion from Leydig 
cells should subsequently be reduced. Although the serum $\mathrm{LH}$ and $\mathrm{FSH}$ levels were decreased during the TP treatment, the extent of reduction of LH levels was greater than that of $\mathrm{FSH}$ levels, and only the serum $\mathrm{FSH}$ levels returned to pre-treatment values during the post-treatment period. These differences are expected to be largely attributable to the effect of inhibin, the main suppressor of FSH secretion in rats (21). The decrease in serum $\mathrm{LH}$ and FSH levels induced by the TP treatment causes a decline in testosterone production by Leydig cells and, therefore, a reduction in the intratesticular testosterone concentration that, in turn, causes a shrunken testis and reduces sperm production in the seminiferous tubules of intact male rats (17). This likely explains the decreased testis weight that was detected in the TP-treated rats in the present study. In contrast to the decline in testicular weight with TP treatment, the seminal vesicle and epididymal weights of the rats increased and the hypertrophy corresponded to mild, though noticeable, histological changes in cell growth and secretion $(14,16,17,22)$.

In contrast to the effects of TP, $B$. superba powder did not alter the serum testosterone, $\mathrm{LH}$, and FSH levels or the weights and histological appearances of the reproductive organs (testis and epididymis) in intact male rats, except that the seminal vesicle weight increased only in the BS-250 group. It was previously reported that $B$. superba significantly reduced serum testosterone levels with no abnormal appearance of the testicular and epididymal histology or tissue weights. However, this study did not determine if there were any changes in the seminal vesicle (7), the most sensitive organ of androgenic or anti-androgenic activity in the Hershberger bioassay $(16,22)$.

Complete orchidectomy caused lower serum testosterone and higher serum FSH and LH levels in orchidectomized rats than in normal male rats. No effects of $B$. superba on the serum testosterone levels of orchidectomized rats were observed in the present study, although BS-50 and BS-250 significantly suppressed the increased serum LH levels. In contrast, serum LH and FSH levels were significantly decreased in TP-treated rats after 15 days of treatment. Thus, we conclude that the doses of $B$. superba administered can partially suppress the hypothalamic-pituitary axis in orchidectomized rats, which seems to indicate the weak androgenic activity of $B$. superba. At present, it is unknown what chemicals in $B$. superba exhibit androgenic activity and further investigation is still needed. $B$. superba root contains the flavonoid and flavonoid glycoside $(4,23)$, which showed inhibitory effects on cAMP phosphodiesterase activity (4).

\section{References}

1. Suntara A. The remedy pamphlet of Kwao Kure Tuber of Luang Anusarnsuntarakromkarnpisit. Chiang Mai: Chiang Mai Upatipongsa Press; 1931.
Currently, three phytoestrogens, daidzein, coumestrol and genistein, have been isolated from the tuberous root of B. superba (24). Genistein reduced the pituitary contents and prostate weights of male mice (25), interfered with the coupling of transmembrane LH receptors to $G$ proteins and suppressed the steroidogenesis of the testicular Leydig cells in adult male rats (26). Coumestrol can suppress the pulsatile LH secretion from the pituitary gland of ovariectomized rats (27). Previously, we reported that Pueraria mirifica, a phytoestrogen-containing herb, can suppress serum LH and $\mathrm{FSH}$ levels in female as well as in male rats, although the response of females was greater than that of males (13). In addition, orchidectomized rats are more sensitive to weak endocrine disruptors than intact rats (28). Taken together with no changes in weight or histological appearances of the epididymis and seminal vesicles in all three BS treatment groups of the orchidectomized rats, this suggests that the decrease in serum LH levels in BS-50- and BS-250-treated rats is caused by a weak estrogenic activity of phytoestrogen constituents in $B$. superba. It is difficult to know if the reduction of $\mathrm{LH}$ levels in orchidectomized rats is due to the estrogenic activity or androgenic activity of $B$. superba. Higher doses of $B$. superba are suggested to be used. However, because the $B$. superba powder suspension has a high viscosity, a dose higher than $250 \mathrm{mg} / \mathrm{kg}$ body weight, the highest dose used in the present study, could not be administered by gavage. Thus, each substance isolated from $B$. superba should be tested separately for androgenic activity as well as estrogenic activity in male rats.

On the basis of the results obtained here in intact and orchidectomized rats, we conclude that $B$. superba needs to work synergistically with an endogenous testosterone to stimulate accessory sex organ in intact animals and can potentially exhibit an $\mathrm{LH}$ reduction effect in orchidectomized animals.

\section{Acknowledgments}

The authors thank Dr. Robert Butcher, Faculty of Science, Chulalongkorn University, for proofreading the manuscript. Research supported in part by the Interdisciplinary Program in Physiology, the Graduate School, the Primate Research Unit, Chulalongkorn University, Thailand and by a Grants-in-Aid for Scientific Research (The 21st Century Center of Excellence Program, E-1) from the Ministry of Education, Culture, Sport, Science and Technology of Japan.

2. Cherdshewasart W, Nimsakul N. Clinical trial of Butea superba, an alternative herbal treatment for erectile dysfunction. Asian J Androl 2003; 5: 243-246. 
3. Tocharus C, Smitasiri Y, Jeenapongsa R. Butea superba Roxb. enhances penile erection in rats. Phytother Res 2006; 20: 484-489.

4. Roengsumran S, Petsom A, Ngamrojanavanich N, Rugsilp $\mathrm{T}$, Sittiwichienwong $\mathrm{P}$, Khorphueng $\mathrm{P}$, et al. Flavonoid and flavonoid glycoside from Butea superba Roxb. and their cAMP phosphodiesterase inhibitory activity. J Sci Res Chula Univ 2000; 25: 169-176.

5. Ingkaninan K, Temkitthawon P, Chuenchom K, Yuyaem T, Thongnoi W. Screening for acetylcholinesterase inhibitory activity in plants used in Thai traditional rejuvenating and neurotonic remedies. J Ethnopharmacol 2003; 89: 261264.

6. Manosroi A, Sanphet K, Saowakon S, Aritajat S, Manosroi J. Effects of Butea superba on reproductive systems of rats. Fitoterapia 2006; 77: 435-438.

7. Cherdshewasart W, Bhuntaku P, Panriansaen R, Dahlan W, Malaivijitnond $\mathrm{S}$. Androgen disruption and toxicity tests of Butea superba Roxb., a traditional herb used for treatment of erectile dysfunction, in male rats. Maturitas 2008; 60: 131137.

8. Malaivijitnond S, Ketsuwan AN, Watanabe G, Taya K, Cherdshewasart W. Androgenic activity of the Thai traditional male potency herb, Butea superba Roxb., in female rats. $J$ Ethnopharmacol 2009; 121: 123-129.

9. Jaroenporn S, Malaivijitnond S, Wattanasirmkit K, Trisomboon H, Watanabe G, Taya K, et al. Effects of Pueraria mirifica, an herb containing phytoestrogens, on reproductive organs and fertility of adult male mice. Endocrine 2006; 30: 93-101.

10. Cherdshewasart W, Cheewasopit W, Picha P. The differential anti-proliferation effect of white (Pueraria mirifica), red (Butea superba), and black (Mucuna collettii) Kwao Krua plants on the growth of MCF-7 cells. J Ethnopharmacol 2004; 93: 255-260.

11. Humason GL. Animal tissue techniques. USA: W.H. Freeman and Company; 1972.

12. Malaivijitnond S, Varavudhi P. Evidence for morphineinduced galactorrhea in male cynomolgus monkeys. $J$ Med Primatol 1998; 27: 1-9.

13. Malaivijitnond S, Kiatthaipipat $P$, Cherdshewasart W, Watanabe G, Taya K. Different effects of Pueraria mirifica, a herb containing phytoestrogens, on $\mathrm{LH}$ and $\mathrm{FSH}$ secretion in gonadectomized female and male rats. J Pharmacol Sci 2004; 96: 428-435.

14. Kang HG, Jeong SH, Cho JH, Kim DG, Park JM, Cho MH. Evaluation of estrogenic and androgenic activity of butylated hydroxyanisole in immature female and castrated rats. Toxicology 2005; 213: 147-156.

15. Nishino T, Wedel T, Schmitt $O$, Schonfelder M, Hirtreiter $\mathrm{C}$, Schulz $\mathrm{T}$, et al. The xenoestrogen bisphenol $\mathrm{A}$ in the Hershberger assay: androgen receptor regulation and morphometrical reactions indicate no major effects. J Steroid
Biochem Mol Biol 2006; 98: 155-163.

16. Owens W, Zeiger E, Walker M, Ashby J, Onyon L, Gray LE Jr. The OECD program to validate the rat Hershberger bioassay to screen compounds for in vivo androgen and antiandrogen responses. Phase 1: use of a potent agonist and a potent antagonist to test the standardized protocol. Environ Health Perspect 2006; 114: 1259-1265.

17. Tinwell H, Friry-Santini C, Rouquie D, Belluco S, Elies L, Pallen C, et al. Evaluation of the antiandrogenic effects of flutamide, DDE, and linuron in the weanling rat assay using organ weight, histopathological, and proteomic approaches. Toxicol Sci 2007; 100: 54-65.

18. Earley CJ, Leonard BE. Androgens, estrogens and their antihormones: effects on body weight and food consumption. Pharmacol Biochem Behav 1979; 11: 211-214.

19. Urasopon N, Hamada Y, Cherdshewasart W, Malaivijitnond S. Preventive effects of Pueraria mirifica on bone loss in ovariectomized rats. Maturitas 2008; 59: 137-148.

20. Porkka-Heiskanen T, Laakso ML, Stenberg D. The effect of testosterone on serum gonadotropins of castrated rats kept under different lighting conditions. Biol Reprod 1992; 46: $1127-1129$

21. Kishi H, Itoh M, Wada S, Yukinari Y, Tanaka Y, Nagamine N, et al. Inhibin is an important factor in the regulation of $\mathrm{FSH}$ secretion in the adult male hamster. Am J Physiol Endocrinol Metab 2000; 278: E744-E751.

22. Stroheker T, Cabaton N, Berges R, Lamothe V, Lhuguenot $\mathrm{JC}$, Chagnon MC. Influence of dietary soy isoflavones on the accessory sex organs of the Wistar rat. Food Chem Toxicol 2003; 41: 1175-1183.

23. Yadava RN, Reddy KI. A new bio-active flavonol glycoside from the stems of Butea superba Roxb. J Asian Nat Prod Res 1998; 1: 139-145.

24. Ma K, Ishikawa T, Seki H, Furihata K, Ueki H, Narimatsu S, et al. Isolation of new isoflavonolignans, Butesuperins $A$ and B, from a Thai miracle herb, Butea superba. Heterocycles 2005; 65: 893-900.

25. Strauss L, Makela S, Joshi S, Huhtaniemi I, Santti R. Genistein exerts estrogen-like effects in male mouse reproductive tract. Mol Cell Endocrinol 1998; 144: 83-93.

26. Hancock KD, Coleman ES, Tao YX, Morrison EE, Braden TD, Kemppainen BW, et al. Genistein decreases androgen biosynthesis in rat Leydig cells by interference with luteinizing hormone-dependent signaling. Toxicol Lett 2009; 184: 169-175.

27. McGarvey C, Cates PA, Brooks A, Swanson IA, Milligan SR, Coen CW, et al. Phytoestrogens and gonadotropin-releasing hormone pulse generator activity and pituitary luteinizing hormone release in the rat. Endocrinology 2001; 142: 12021208.

28. Gray LE Jr, Wilson V, Noriega N, Lambright C, Furr J, Stoker $\mathrm{TE}$, et al. Use of the laboratory rat as a model in endocrine disruptor screening and testing. ILAR J 2004; 45: 425-437. 